\section{Minimal intervention dentistry: part 4. Detection and diagnosis of initial caries lesions}

\author{
A. Guerrieri, ${ }^{1}$ C. Gaucher, ${ }^{2}$ E. Bonte ${ }^{3}$ and J. J. Lasfargues ${ }^{4}$
}

VERIFIABLE CPD PAPER

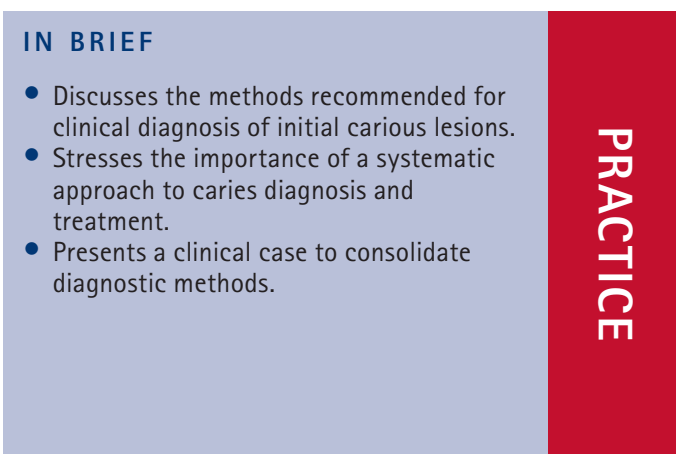

\begin{abstract}
The detection of carious lesions is focused on the identification of early mineral changes to allow the demineralisation process to be managed by non-invasive interventions. The methods recommended for clinical diagnosis of initial carious lesions are discussed and illustrated. These include the early detection of lesions, evaluation of the extent of the lesion and its state of activity and the establishment of appropriate monitoring. The place of modern tools, including those based on fluorescence, is discussed. These can help inform patients. They are also potentially useful in regular control visits to monitor the progression or regression of early lesions. A rigorous and systematic approach to caries diagnosis is essential to establish a care plan for the disease and to identify preventive measures based on more precise diagnosis and to reduce reliance on restorative measures.
\end{abstract}

\section{INTRODUCTION}

The initial caries lesion can be defined as a primary lesion which has not reached the stage of an established lesion with cavitation. It is therefore amenable to

\section{MINIMAL INTERVENTION DENTISTRY}

1. From 'compulsive' restorative dentistry to rational therapeutic strategies

2. Caries risk assessment in adults

3. Paediatric dental care - prevention and management protocols using caries risk assessment for infants and young children

4. Detection and diagnosis of initial caries lesions

5. Atraumatic restorative treatment (ART) a minimum intervention and minimally invasive approach for the management of dental caries

6. Caries inhibition by resin infiltration

7. Minimally invasive operative caries management - rationale and techniques This paper is adapted from: Guerrieri A, Gaucher C, Bonte $E_{\text {, }}$ Lasfargues $J$ J. Détection et diagnostic des lésions carieuse initiales. Réalités Cliniques 2011; 22: 233-244

${ }^{-4}$ Faculté de Chirurgie Dentaire, Université PARIS DESCARTES (1 rue Maurice Arnoux, 92120 Montrouge) et Service d'Odontologie, Hôpital Bretonneau, APHP

(2 rue Carpeaux, 75018 Paris), France

${ }^{*}$ Correspondence to: Professor Jean-Jacques Lasfargues Email: jean-jacques.lasfargues@brt.aphp.fr;

Tel: +3315311 1430

\section{Accepted 21 June}

DOI: 10.1038/sj.bdj.2012.1087

${ }^{\circledR}$ British Dental Journal 2012; 213: 551-557 being treated by non-invasive procedures including ultra-conservative or minimal intervention dentistry.

The detection of carious lesions at an early stage is necessary in order to implement preventive and interceptive treatment strategies. In daily practice, the diagnosis of initial lesions is not always simple; it is often subjective and based on the clinician's clinical sense. For this reason, the search is on for more specific and sensitive tools, using new technologies, to help the practitioner diagnose initial caries lesions as precisely as possible. The purpose of this paper is to review the recommended clinical methods for diagnosing initial caries lesions and to examine recent tools for early detection of these lesions.

\section{BACKGROUND}

The initial enamel lesion results from an imbalance between the processes of demineralisation and remineralisation. The first changes in enamel appear at those sites where there is plaque biofilm retention and stagnation. The demineralisation alters the enamel surface, which becomes micro-porous, and with an opaque and matt appearance, characteristic of a white spot lesion. Acid penetration along the sheath of the enamel prism leads to the dissolution of crystalline spaces adjacent to the lesion and progressing to the enamel-dentine junction (EDJ) and, in the absence of treatment, cavitation occurs. ${ }^{1-3}$

High evidence-level studies are in agreement that the ideal tool for detection of the initial lesion, the 'gold standard,' has not yet been identified. Such a tool should have both a high level of sensitivity (the ability to detect disease when it exists) and a high level of specificity (the ability to confirm the absence of disease). The conventional and validated tools for detecting early carious lesions include visual and tactile examination and radiography (bitewings). These methods have good specificity but only moderate sensitivity and are relatively 'operator-dependent'. ${ }^{4-6}$ The combination of clinical examination and bitewing radiographs nevertheless allows diagnoses with improved sensitivity and specificity. Some new technologies are appearing and it is of interest to link them with standard clinical practices, with a view to improving caries detection and diagnosis. ${ }^{3}$

\section{THE STANDARD CLINICAL APPROACH}

Systematised caries diagnostic procedures consist of three stages: the detection of a lesion, evaluation of its severity (depth) and its level of activity. ${ }^{7,8}$ Before an examination, the practitioner will have noted the general context of caries activity. The 
principle general risk factors should be noted: age group, health state and use of medications, lifestyle, oral hygiene, nutrition and use of fluorides (Figs 1 and 2). Evaluation of individual caries risk cannot be separated from the actual diagnosis of carious lesions. It is essential to categorise a patient as being at low or high risk of caries for the correct choice of preventive, interceptive, or therapeutic care.

\section{INITIAL CLINICAL EXAMINATION}

The purpose of the examination is to detect visually changes of colour, translucency and structure of the enamel. An initial inspection, tooth by tooth, on wet surfaces can spot cavities and brown or white stains. Periodontal status and restorations may also be checked initially. At this stage, caries activity must be evaluated by checking the build-up of plaque biofilm and the gingival pathology at suspect sites. A blunt/rounded probe (a periodontal probe is appropriate) may be used, with gentle force (Fig. 3). Clinical parameters that indicate and quantify the activity state of a single carious lesion are, according to Ekstrand: ${ }^{8}$

- The appearance of the lesion, correlated with its severity (extension, depth)

- The position of the lesion (in an area in favouring plaque build-up or not)

- Tactile perceptions on probing (used to assess the presence of surface deposits and the roughness of the enamel)

- The status of the gingival margin in relation to the areas of interest (assessed by the absence or presence of bleeding caused by a careful probing).

\section{EXTENSIVE CLINICAL OBSERVATION}

Observation is used to classify each lesion according to its site and its stage of advancement, with a view to therapy. ${ }^{3}$ Pre-cleaning is fundamental to the quality of diagnosis, both for the direct visual examination and for the use of complementary diagnostic aids such as fluorescence-based techniques. ${ }^{9}$ Undertaken with a rotating brush and prophylactic paste, or by air-polishing, the aim is elimination of the surface biofilm and deposits. Once cleaned, the suspect sites are dried and inspected individually. The use of visual aids (magnifying loupes, minimum $\times 2.5$ ) greatly improves the detection rate of initial carious lesions. ${ }^{10}$ The signs to look for

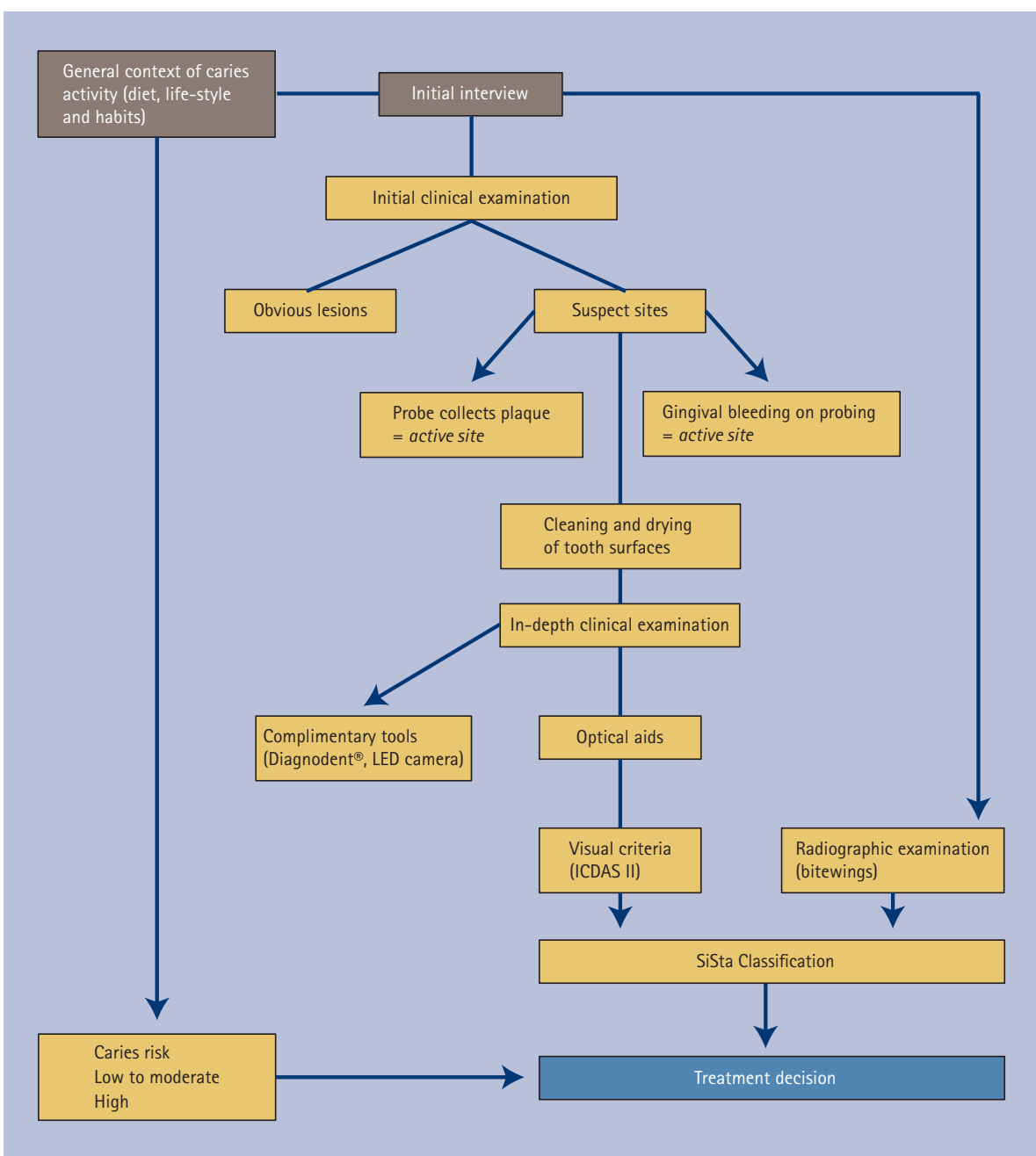

Fig. 1 Flow-chart of the practical approach to assessment of initial carious lesions (from Lasfargues and Colon, 2010) ${ }^{3}$

are changes in colour and translucency that indicate the state of demineralisation of surfaces and sub-surface zones compared with adjacent healthy areas. These visible signs indicating caries have been rationalised in a classification system, the International Caries Detection and Assessment System (ICDAS). ${ }^{11}$ The classification includes six codes. Initial lesions are mainly covered by codes 1 and 2 .

- ICDAS II Code 0: the tooth is healthy

- ICDAS II Code 1: the tooth has a lesion visible only after drying and histology reveals that the lesion is limited to the external half of enamel

- ICDAS II Code 2: the lesion penetrates the full thickness of enamel. Clinically, an opacity or discoloration distinctly visible without air-drying is apparent but without cavitation (Fig. 4).

A statistically significant correlation exists between the anatomical and histological stages of lesions and the major

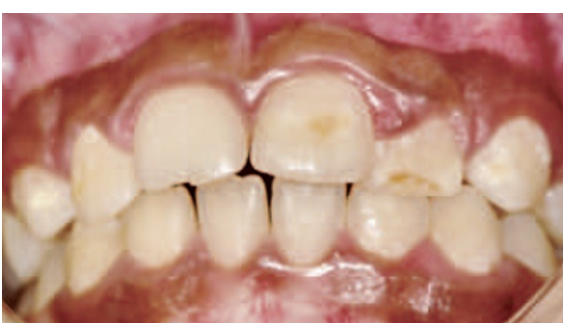

Fig. 2a Young patient presenting with a high caries risk, as evidenced by the presence of multiple white-spot demineralisations and severe gingivitis

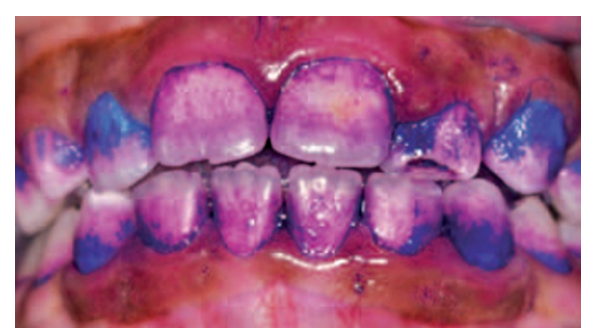

Fig. $2 b$ Close-up of area of plaque retention, indicating high disease activity

visual signs. ${ }^{12}$ Carious lesions thus identified are classified on the ICDAS system according to the site: occlusal (site 1), 


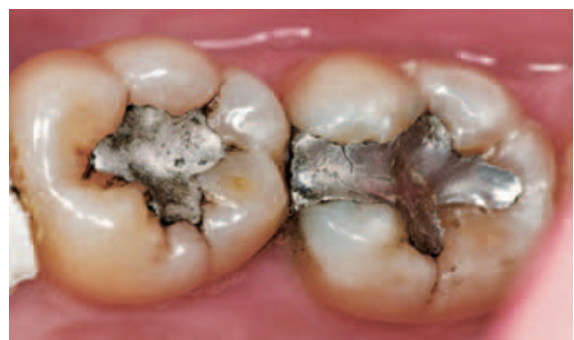

Fig. 3a Detection of a proximal carious lesion. Identification of a suspected site of carious activity distal to 36

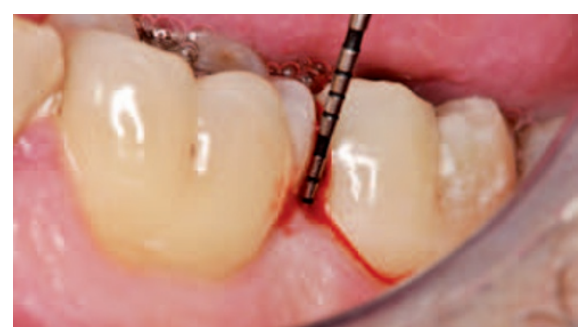

Fig. 3b Carious activity confirmed by the presence of bleeding on probing with the periodontal probe, allowing the severity of the lesion to be evaluated

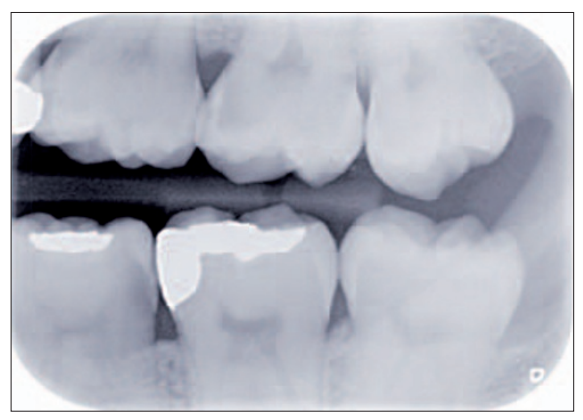

Fig. 3c Bitewing showing SiSta classification Stage 2

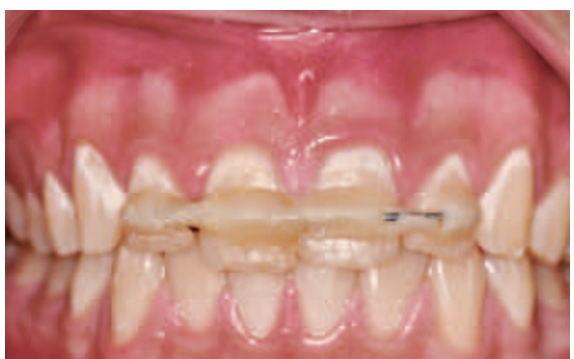

Fig. 4 Multiple ICDAS II score initial lesions (breach of any thickness of cervical enamel). Note the white areas, clearly visible without drying

proximal (site 2), and cervical (site 3), then according to their stage (Table 1).

\section{VISUAL EXAMINATION ASSISTED BY PROBING}

Tactile sensation has long been the principal diagnostic tool in cariology, involving the use of a sharp dental explorer. It has been demonstrated that probing does

\begin{tabular}{|c|c|c|c|c|}
\hline $\begin{array}{l}\text { ICDAS } \\
\text { Code }\end{array}$ & $\begin{array}{l}\text { Criteria for visual } \\
\text { lesion detection }\end{array}$ & $\begin{array}{l}\text { Degree of severity } \\
\text { of lesion }\end{array}$ & $\begin{array}{l}\text { SiSta* } \\
\text { stage }\end{array}$ & Therapeutic options \\
\hline 0 & Sound surface & & & Not necessary \\
\hline 1 & $\begin{array}{l}\text { Earliest optical change, } \\
\text { visible on drying enamel }\end{array}$ & $\begin{array}{l}\text { Demineralisation in outer } \\
\text { third of enamel }\end{array}$ & \multirow[b]{2}{*}{0} & \multirow{2}{*}{$\begin{array}{l}\text { Minimal intervention; } \\
\text { non-invasive care, } \\
\text { remineralisation or sealant }\end{array}$} \\
\hline 2 & $\begin{array}{l}\text { Clear enamel change; white } \\
\text { or brown blemishes, visible } \\
\text { without drying }\end{array}$ & $\begin{array}{l}\text { Demineralisation reaching } \\
\text { the inner third of enamel, } \\
\text { possibly the ADJ }\end{array}$ & & \\
\hline 3 & Localised break in enamel & $\begin{array}{l}\text { Demineralisation of outer } \\
\text { third of dentine }\end{array}$ & \multirow[b]{2}{*}{1 and 2} & \multirow[b]{2}{*}{$\begin{array}{l}\text { Minimal intervention; } \\
\text { adhesive ultra conservative } \\
\text { restoration }\end{array}$} \\
\hline 4 & Dentine not visible & $\begin{array}{l}\text { Demineralisation of } \\
\text { middle third of dentine, } \\
\text { no weakening of dental } \\
\text { crown structure }\end{array}$ & & \\
\hline 5 & $\begin{array}{l}\text { Enamel opaque or greyish, } \\
\text { suggestive of an underlying } \\
\text { dentine lesion, with or } \\
\text { without enamel cavitation }\end{array}$ & $\begin{array}{l}\text { Demineralisation of middle } \\
\text { third of dentine, weakening } \\
\text { of dental crown structure }\end{array}$ & \multirow{2}{*}{3 and 4} & \multirow{2}{*}{$\begin{array}{l}\text { Operative dental care; } \\
\text { functional crown } \\
\text { restoration with or } \\
\text { without cusp coverage }\end{array}$} \\
\hline 6 & Dentine cavity & $\begin{array}{l}\text { Demineralisation of inner } \\
\text { third of dentine, } \\
\text { undermining of cusp } \\
\text { structure and support }\end{array}$ & & \\
\hline
\end{tabular}

not improve the diagnostic sensitivity of visual examination, especially in detecting lesions in pits and occlusal fissures. Indeed, the result of this subjective method depends on the size of the probe tip, the resistance of the enamel and the force exerted by the probe. Furthermore, probing can cause iatrogenic damage to enamel (and loss of the possibility of remineralisation) so favouring lesion progression. ${ }^{13}$ Probing with a sharp dental explorer cannot be considered a reliable technique for detection of carious lesions.

\section{RADIOGRAPHIC EVALUATION}

Bitewing radiographs are the method of choice for early detection of carious lesions, especially on proximal surfaces. Radiographic examination reveals, on average, twice as many proximal lesions extending into dentine as simple visual examination. Radiographic examination also allows the depth of a carious lesion to be estimated, useful for care planning. In the permanent dentition, two bitewing radiographs are recommended to cover directly and tangentially all proximal surfaces of the molar-premolar segment. The technique involves using a specific film holder with a guide rod and a collimator ring (Rinn angulator). This system allows radiographs to be reproduced at time intervals appropriate for the proper longitudinal follow-up (control) of incipient carious lesions.

\section{NEW DIAGNOSTIC AIDS}

None of the new caries detection techniques developed in recent years is 100\% reliable when used alone. They complement the systematic approach already described, with, for the most validated, an increase in detection sensitivity when combined with conventional techniques. ${ }^{14,15}$ Their development is based on the need for increased detection sensitivity to allow lesions to be identified as early as possible (particularly before invasive restoration becomes necessary). Today the treatment of initial lesions is well understood, ${ }^{16}$ as is the need for early caries lesion detection and diagnosis.

The new diagnostic tools are classified on the basis of the physical principles that underpin them. ${ }^{17}$ The most prominent include transillumination (Diagno.cam, Kavo ${ }^{\circledR}$ ), and fluorescence systems (DIAGNOdent, Kavo ${ }^{\circledR}$; CS 1600 Kodak; VistaCam iX, DürrDental ${ }^{\circledR}$; SoproLife, Acteon ${ }^{\circledR}$.

\section{OPTICAL TECHNIQUES}

\section{Optical aids}

The visual examination requires optical magnification to be properly conducted. This is not a matter of a microscope for clinical use for the detection of early carious lesions. The use of Galilean loupes (magnification $\times 2-5$ ) is satisfactory for daily practice. The practitioner may choose the most ergonomically appropriate type 
(glasses, headband, helmet), coupled ideally to an integrated halogen/LED lighting system.

\section{Scanned images}

Conventional intraoral cameras allow direct viewing of the captured image and digital archiving is simple. Such images are particularly useful for patient teaching and motivation purposes but their quality is not always satisfactory for diagnosis. ${ }^{17}$

\section{Fluorescence systems}

Fluorescence is light emission provoked by excitation of the molecules in a material due to the absorption of high energy light. This phenomenon occurs with all natural materials. In the tooth, natural fluorescence is attributed to the proteins that make up the enamel and dentine matrices. It may also occur when bacterial metabolites from the carious process, plaque, composite resins or prophylactic paste residue absorb high energy light. Before using devices based on fluorescence, it is important to undertake meticulous cleaning, rinsing and drying of the surfaces to be studied so as to eliminate as much as possible matter which could cause confusion (Fig. 5).

\section{Infrared laser}

The DIAGNOdent ${ }^{\circledR}$ and DIAGNOdent pen ${ }^{\circledR}$ were developed following the work of Hibst and Paulus on dental fluorescence in response to absorption of red light, in the late 1990s. The red light and the subsequent fluorescence emissions are carried via optical fibres. The return signal is filtered and modulated to indicate the degree of mineralisation of the examined surface on a scale from 1 to 99, displayed on a screen. Some authors agree that this system has better sensitivity than visual or radiographic examination. ${ }^{18-21}$ Its specificity is acceptable but its reproducibility remains controversial. ${ }^{22-24}$ Using the DIAGNOdent pen ${ }^{\circledR}$ is easier than its predecessor because the hand piece is no longer connected to a monitor by an optical cord. On the other hand, its use requires some precautions: the tips must be aligned correctly on the test surfaces, thorough cleaning and drying without dehydration and careful scanning of the entire surface with the repeating beep pulses indicating good signal reception.
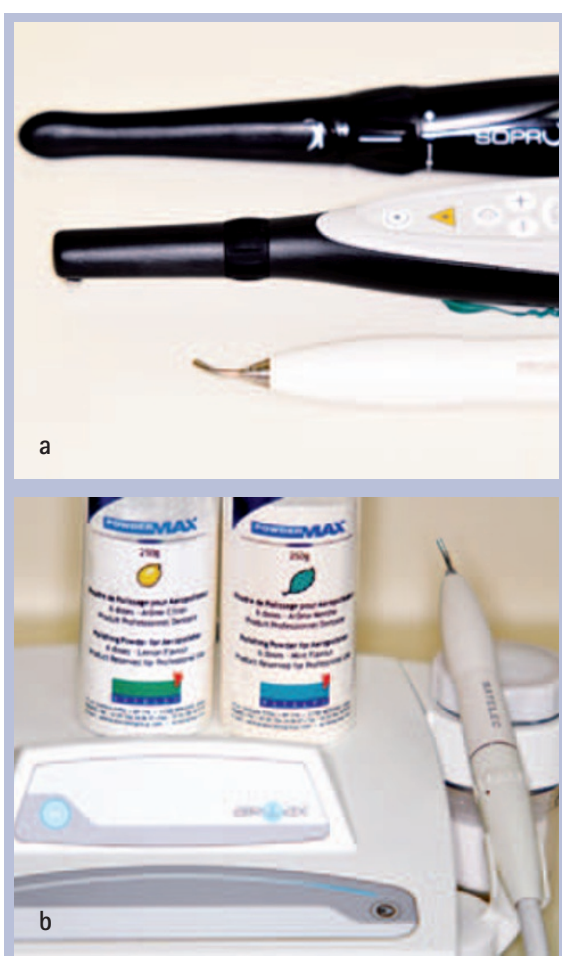

Fig. 5 Use of modern caries diagnosis tools: (a) diagnostic systems such as the SoproLife ${ }^{\circledR}$ camera (Acteon) and the DIAGNODENT ${ }^{\circledR}$ pen (Kavo) should be used with (b) an air-polishing system to preclean surfaces

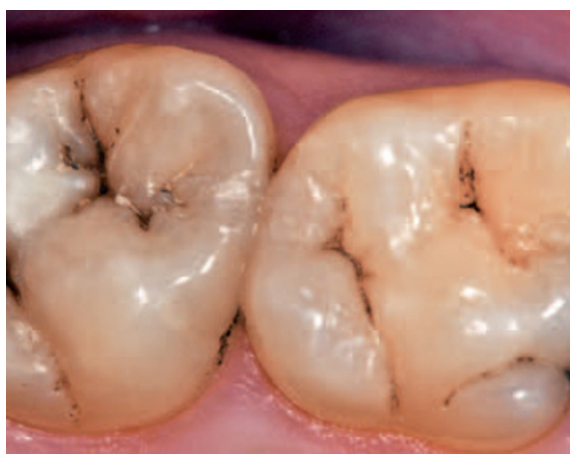

Fig. 5c Clinical examination reveals stained fissures, often considered as affected and treated as carious lesions

\section{Quantitative light fluorescence (QLF)}

This technique uses an intraoral camera with CCD technology linked with system for emitting light in the blue/blue-green wavelengths. The fluorescence of the teeth is rendered on a screen after the blue light is filtered out, leaving green light for the image. Demineralisation greater than 5\% results in a dark spot against the healthy enamel, which is green coloured. This system has been considered to be superior to visual examination for detection of initial carious lesions but confounding factors must be taken into account. Linking QLF



Fig. 5d An air-polisher, here the Air Max ${ }^{\top M}$ by Satelec. It uses a $250 \mu \mathrm{m}$ grain powder in a wet environment (it is possible to choose the flavour)
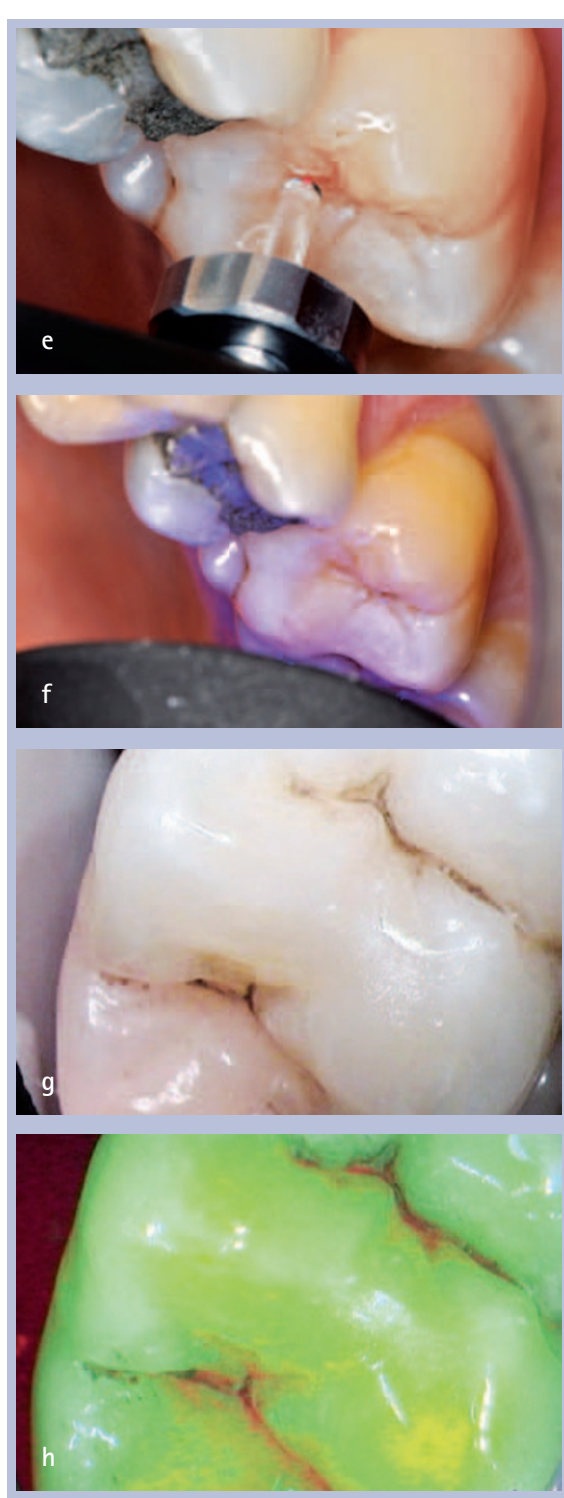

Fig. 5e After cleaning and drying, the DIAGNOdent ${ }^{\circledR}$ does not indicate the presence of a lesion nor does ( $f$ ) the fluorescence camera used in diagnostic mode with $(\mathrm{g})$ white light or (h) polarised light (SoproLife ${ }^{\circledR}$, Acteon)

with visual examination results in significantly increased detection sensitivity of initial lesions. The extended time required for acquisition of the images makes the use of this technology impractical in daily practice. . $^{14,17,25,26}$ 


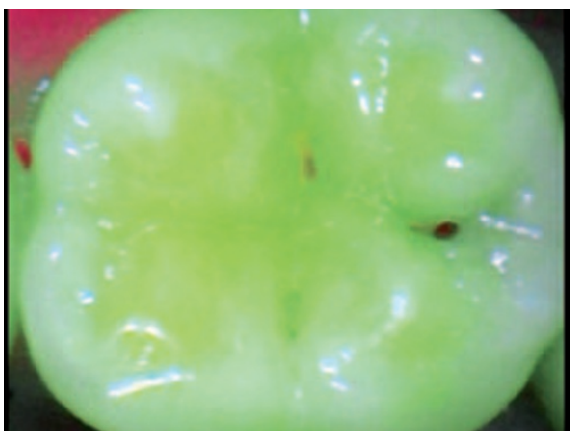

Fig. 6a Using the SoproLife ${ }^{\circledR}$ camera (Acteon) for the diagnosis and treatment of SiSta 1.1 lesions. After cleaning and drying the tooth surfaces, visualisation of the lesion in diagnostic mode with fluorescence

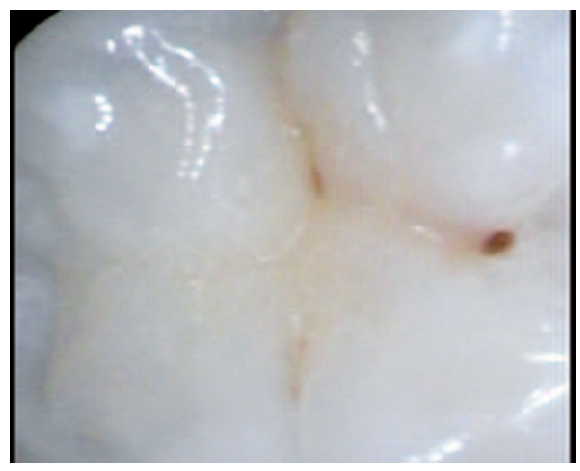

Fig. $6 \mathrm{~b}$ Visualisation of the lesion in diagnostic mode without fluorescence

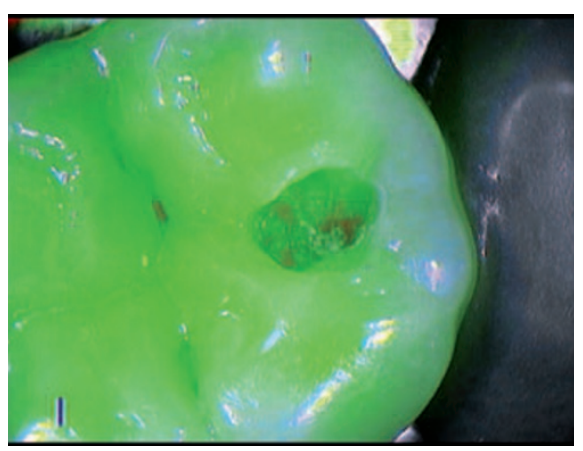

Fig. 6c During the removal of carious tissue, observing the cavity in treatment mode allows the 'red' caries mark to become more visible. The visual and tactile judgment of the practitioner remains nevertheless the salient factor for assessing the amount of tissue to be removed; the camera does not differentiate between layers of infected or affected carious tissue

\section{LED cameras}

The newest detection system for carious lesions is the use of intraoral cameras with LED technology. These systems illuminate the tooth, record the fluorescence of the dental tissue and enhance the image using dedicated software. Clinical studies are underway to confirm their usefulness. The Vista Proof ${ }^{\circledR}$ camera is used with DBSWIN software (Dürr Dental AG) which can also analyse digital radiographs. As with QLF systems, the healthy enamel appears green.

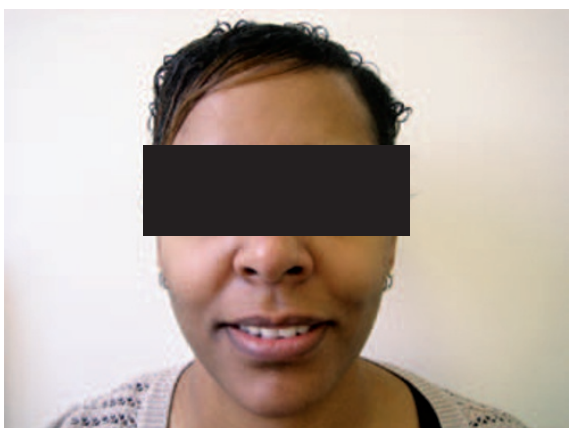

Fig. 7a Facial view of the patient, Mrs A, who attended for a dental assessment before orthodontic treatment

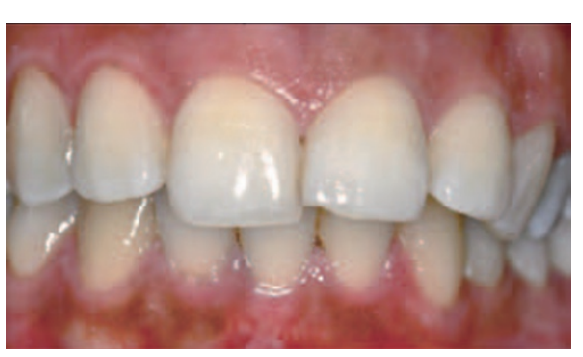

Fig. 7b Frontal view of the anterior dentition

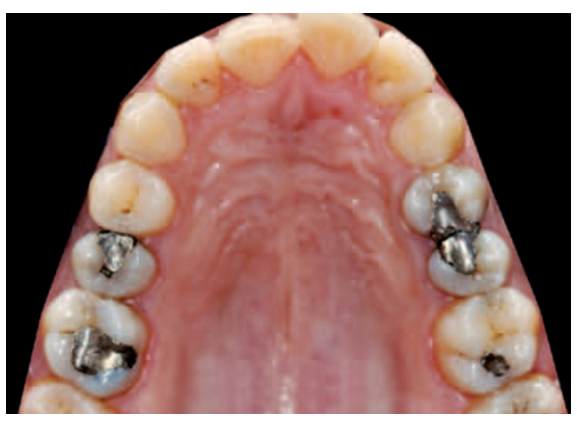

Fig. 7c Occlusal view of the maxillary arch

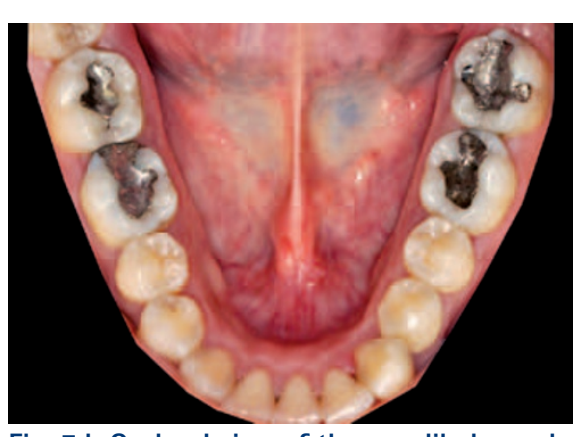

Fig. 7d Occlusal view of the mandibular arch

Demineralised enamel appears blue and dentine is yellow to red, depending on the severity of the demineralisation..$^{27}$ This device was recently improved (VistaCam $\mathrm{iX}^{\circledR}$ ).

The fluoLED camera Sopro-Life ${ }^{\circledR}$ offers fluorescence images in two modes: a diagnostic mode and processing mode. Healthy tissues appear green (blue in areas with very thick enamel) and carious tissue is light to very dark red. In diagnostic mode, the distribution of colours is limited to those observed on the tooth while, in processing
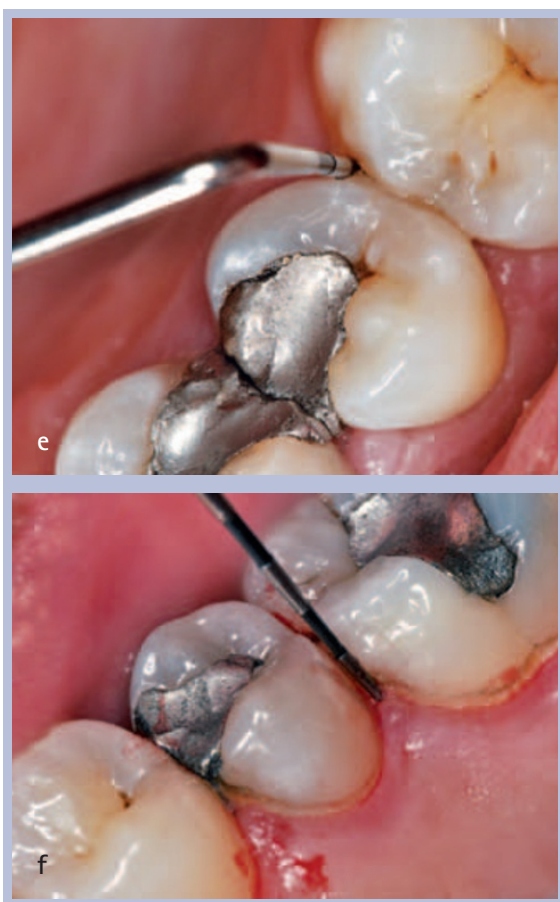

Figs $7 e$ and $f$ Checking the accumulation of plaque and gingival conditions at the 25-26 and 15-16 embrasures

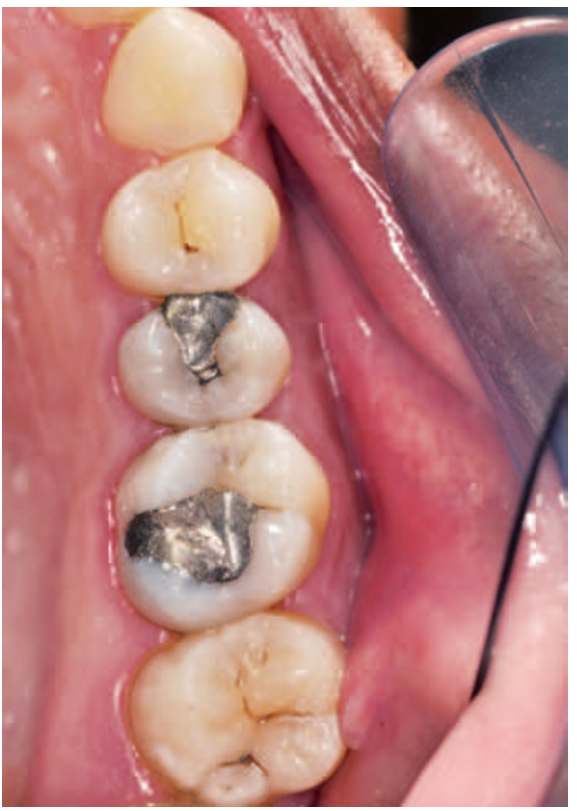

Fig. $7 \mathrm{~g}$ Clinical details of Quadrant 1

mode, the range of red is amplified to guide the practitioner in his elimination of carious tissue (Fig. 6). ${ }^{28}$ Finally, there is a 'day light' mode that allows intraoral photographs and videos to be made.

Research and development of these new technologies should lead to further improvements in their sensitivity, specificity and reproducibility to facilitate the reliable and objective quantitative diagnosis of carious lesions. Beyond the pre- and during-operative diagnostic stages, the 


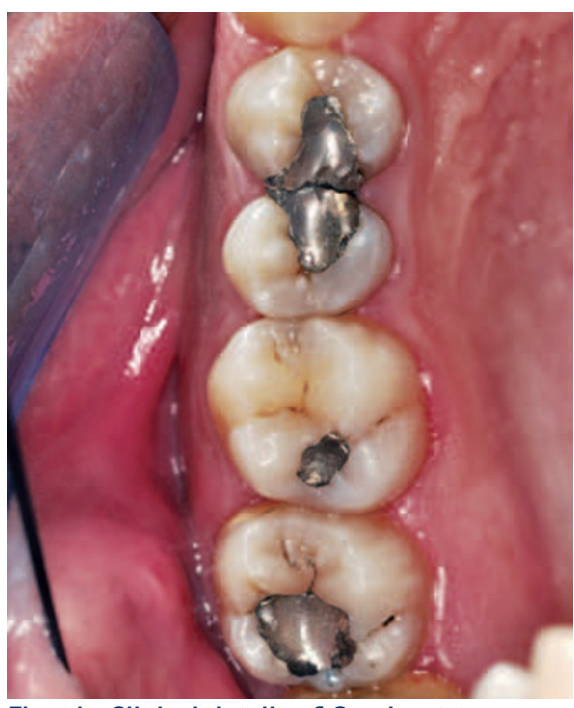

Fig. 7h Clinical details of Quadrant 2

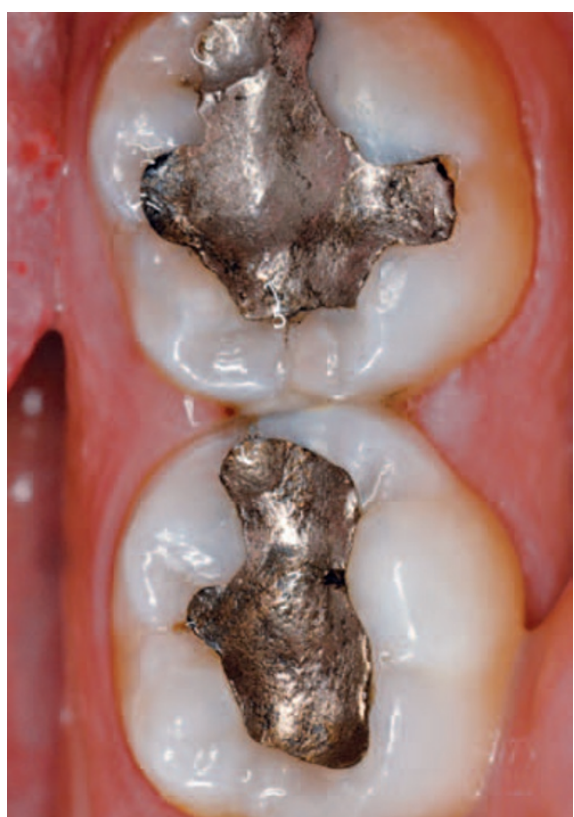

Fig. 7i Clinical details of Quadrant 3

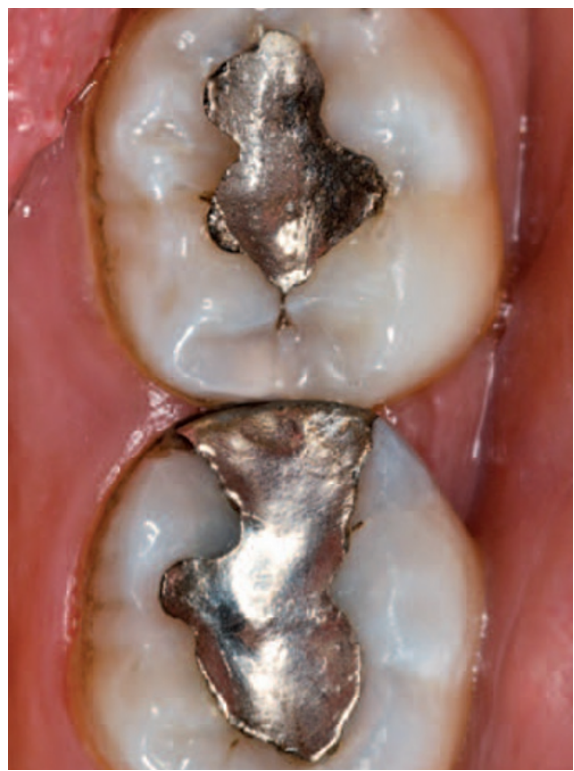

Fig. 7j Clinical details of Quadrant 4; note the lesion on mesial surface of 47 main interest in these new technologies for minimum intervention dentistry will be to enable remineralisation of initial lesions to be monitored. It is essential, however, to understand that all detection technologies should be used in combination, without sole reliance on one particular method. This will increase the sensitivity and specificity of caries lesion detection.

\section{CLINICAL CASE}

Mrs A, aged 30 years, consulted for an oral check before commencing orthodontic treatment (angle Class II associated with 21 labially positioned teeth). The patient was cooperative but not easily available for dental appointments (Fig. 7).

During the initial consultation, inspection revealed absence of pain and a healthy lifestyle. A food diary conducted the week following the consultation indicated a high sugar intake. At the preliminary oral examination, oral hygiene appeared less than perfect (moderate quantities of plaque) despite brushing twice daily. The presence of defective amalgam restorations and noticeable superficial gingivitis was noted.

After air-polishing to eliminate surface discolouration and the biofilm (Fig. 5), a more detailed observation using optical aids was undertaken of suspect sites, particularly in the premolar and molar areas. Gingival condition and the accumulation of plaque were audited at the embrasures with the aid of a periodontal probe. Gingival bleeding on probing was noticed in the region of teeth 25-26 (Fig. 7e) and 15-16 (Fig. 7f), raising suspicions of the presence of proximal lesions due to plaque retention in these confined areas. Changed colour in the mesial marginal ridge of 47 (Fig. 7j) indicated a dentinal lesion with undermined enamel (ICDAS code 4). At this stage, bitewing radiographs in these two regions was deemed necessary to confirm the presence or absence of lesions and, if present, their extent. The radiographs indicated initial caries in the right sector: SiSta 2.0 on $15 \mathrm{D}$ and $14 \mathrm{D}$ as well as $44 \mathrm{D}$ and $45 \mathrm{D}$, and SiSta 2.2 on $47 \mathrm{M}$ and, in the left sector: SiSta 2.0 on $24 \mathrm{M}, 25 \mathrm{D}, 26 \mathrm{M}$ and SiSta 2.0 on 36D and 37M.

\section{Ultraconservative minimal intervention dentistry}

Analysis of all risk factors and predictors revealed by the dietary diary and the clinical examination, indicated a high caries

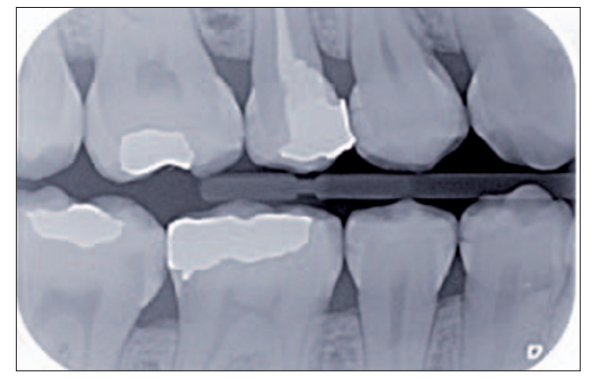

Fig. 7k Bitewings of right premolar area



Fig. 7l Bitewing of right molar area

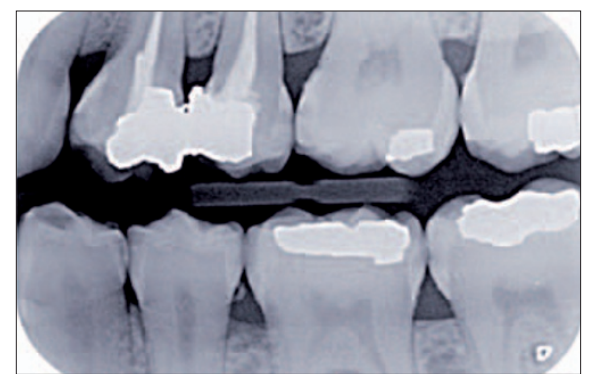

Fig. $7 \mathrm{~m}$ Bitewing of left premolar area

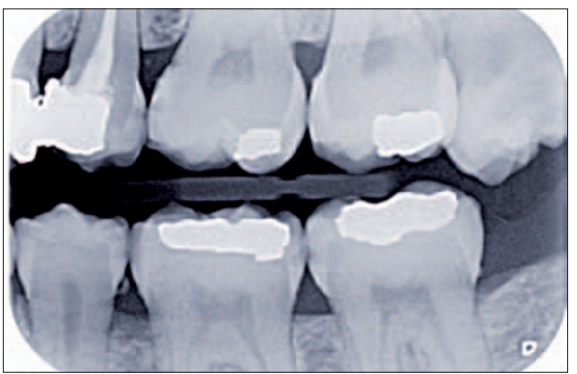

Fig. 7n Bitewings of left molar area

risk requiring management and follow-up every three months (Table 2). The following treatment objectives were proposed for this patient:

- Control caries disease by lowering caries risk (plaque control and dietary advice)

- Treatment of non-cavitated lesions using non-operative methods (remineralisation or resin impregnation)

- Treatment of cavitated lesions with adhesive restorations (composite)

- Replacement of defective amalgam restorations by long-lasting provisional adhesive restorations

- Prevention of recurrent caries during 


\begin{tabular}{|c|c|c|}
\hline Risk factors and predictors & Present & Absent \\
\hline \multicolumn{3}{|l|}{ New carious lesions } \\
\hline New active lesions in the past 3 years & 9 lesions & \\
\hline Restorations placed in the past 3 years & & $x$ \\
\hline \multicolumn{3}{|l|}{ Oral factors (hygiene, plaque, saliva) } \\
\hline Twice daily toothbrushing & $x$ & \\
\hline Topical fluoride (toothpaste, mouth rinse) & & $x$ \\
\hline Dental plaque accumulation & $x$ & \\
\hline Gingival bleeding (on probing, spontaneous) & $x$ & \\
\hline Salivary pH and stimulated salivary flow & & $x$ \\
\hline Increased counts, Lactobacillus and S. mutans & Not done & \\
\hline \multicolumn{3}{|l|}{ General factors (age, nutrition, health) } \\
\hline Risk age group (child, adolescent, senior (reduced autonomy) & & $x$ \\
\hline Sugar consumption, snacking, frequent sugary drinks & $x$ & \\
\hline Boulimia, obesity, diabetes & & $x$ \\
\hline Pregnancy & & $x$ \\
\hline Dry mouth due to medication; addiction & & $x$ \\
\hline Sjögren's syndrome & & $x$ \\
\hline Chemotherapy, radiotherapy of head and neck region & & $x$ \\
\hline \multicolumn{3}{|l|}{ Behavioural factors } \\
\hline Risk occupation; injurious cultural habits & & $x$ \\
\hline Low socio-economic status, unemployed & & $x$ \\
\hline Caries risk & \multicolumn{2}{|l|}{ High } \\
\hline Frequency of caries check-up & \multicolumn{2}{|l|}{3 months } \\
\hline
\end{tabular}

orthodontic treatment by active maintenance.

\section{CONCLUSIONS}

In recent years, methods of detection of early carious lesions have evolved considerably, moving firstly towards the identification of the earliest mineral changes and then to controlling the demineralisation process using non-operative procedures. Previously an indiscriminate routine task, caries diagnosis has become a fully-fledged, codified discipline which demands of the practitioner precise knowledge, rigor and time. In addition to the identification of risk factors and the early detection of lesions, it is essential to evaluate the extent of each lesion (noncavitated $v s$ cavitated) and its status (active or arrested) so as to establish a monitoring procedure and predict the outcome, as for any other disease. Such a systematic approach should lead to a care plan for caries, based on prophylactic measures with minimal use of restorative measures, leading to better patient oral health.

None of the new tools designed to enhance and facilitate caries diagnosis is yet proven, so there is still no absolute substitute for the traditional clinical examination and radiographic bitewing examination. The technologies, particularly those based on fluorescence, may nevertheless assist in raising the awareness and motivation of patients; they are also interesting for their monitoring potential and controlling the process of regression/ progression over periodic intervals.

The authors would like to thank Claudie

Damour - Terrasson, President and publishing director of the Groupe ID Espace - L'Information Dentaire, Paris France, for the authorisation of translation and publication of the series in the BDJ.

1. Haikel Y. Carie dentaire. In Piette $\mathrm{E}_{\text {, Goldberg M }}$ (eds) La dent normale et pathologique. pp 99-124. Bruxelles: De Boeck Supérieur, 2001.

2. Fejerskov 0, Kidd E A M. Dental caries. The disease and its clinical management. Copenhagen: Blackwell Munksgaard. 2003.

3. Lasfargues J J, Colon P. Odontologie conservatrice et restauratrice. Tome 1: une approche médicale globale. France: Wolters Kluwer, 2010.

4. Bader J D, Shugars D A, Bonito A J. Systematic reviews of selected dental caries diagnostic and management methods. J Dent Educ 2001; 65: 960-968.

5. Selwitz R H, Ismail A I, Pitts N B. Dental caries. Lancet 2007: 369: 51-59.

6. Ewoldsen N, Koka S. There are no clearly superior methods for diagnosing, predicting, and noninvasively treating dental caries. J Evid Based Dent Pract 2010; 10: 16-17.
7. Pitts N B. Modern concepts of caries measurement. J Dent Res 2004; 83: C43-C47.

8. Ekstrand K R, Martignon S, Ricketts D J, Ovist V. Detection and activity assessment of primary coronal caries lesions: a methodologic study. Oper Dent 2007; 32: 225-235.

9. Lussi A, Longbottom C, Gygax M, Braig F. Influence of professional cleaning and drying of occlusal surfaces on laser fluorescence in vivo. Caries Res 2005; 39: 284-286.

10. Erten H, Uçtasli M B, Akarslan Z Z, Uzun O, Baspinar E. The assessment of unaided visual examination, intra-oral camera and operating microscope for the detection of occlusal caries lesions. Oper Dent 2005: 30: 190-194.

11. Ismail A I, Coordinating ICDAS Committee. Rationale and evidence for the international caries detection and assessment system (ICDAS II). In Stookey G (ed) Proceedings of the 7th Indiana Conference, Indianapolis. pp161-222. Indiana: 2005.

12. Ekstrand K R, Ricketts D N, Kidd E A. Reproducibility and accuracy of three methods for assessment of demineralization depth on the occlusal surface: an in vitro examination. Caries Res 1997; 31: 224-231.

13. Kuhnisch J, Dietz W, Stosser L, Hickel R, HeinrichWeltzien R. Effects of dental probing on occlusal surfaces - a scanning electron microscopy evaluation. Caries Res 2007; 41: 43-48.

14. Ferreira Zandoná A, Santiago E, Eckert G, Fontana $M$, Ando M, Zero D T. Use of ICDAS combined with quantitative light-induced fluorescence as a caries detection method. Caries Res 2010; 44: 317-322.

15. Banerjee A, Cook R, Kellow S, Shah K, Festy F, Sherriff M, Watson T. A confocal micro-endoscopic investigation of the relationship between the microhardness of carious dentine and its autofluorescence. Eur J Oral Sci 2010; 118: 75-79.

16. Doméjean-Orliaguet $S$, Banerjee $A$, Gaucher $C$ et al. Minimum Intervention Treatment Plan (MITP) practical implementation in general dental practice. J Minim Interv Dent 2009; 2: 103-123.

17. Pretty I A. Caries detection and diagnosis: novel technologies. J Dent 2006; 34: 727-739.

18. Lussi A, Francescut P. Performance of conventional and new methods for the detection of occlusal caries in deciduous teeth. Caries Res 2003; 37: 2-7.

19. Lussi A, Hellwig E. Risk assessment and preventive measures. Monogr Oral Sci 2006; 20: 190-199.

20. Shi $X$, Traneaeus $S$, Angmar-Månsson B. Fluorescence methods. In Wilson N H F (ed) Minimally invasive dentistry. The management of caries. pp 40-46. UK: Quintessence Books, 2007.

21. Rodrigues J A, Hug I, Diniz M B, Lussi A. Performance of fluorescence methods, radiographic examination and ICDAS II on occlusal surfaces in vitro. Caries Res 2008; 42: 297-304.

22. Lussi A, Hack A, Hug I, Heckenberger H, Megert $B$, Stich $\mathrm{H}$. Detection of approximal caries with a new laser fluorescence device. Caries Res 2006; 40: 97-103.

23. Spiguel M H, Tovo M F, Kramer P F, Franco K S, Alves $K M$, Delbem A C. Evaluation of laser fluorescence in the monitoring of the initial stage of the deremineralization process: an in vitro and in situ study. Caries Res 2009; 43: 302-307.

24. Ghaname ES, Ritter A V, Heymann H O, Vann W F $J r$, Shugars D A, Bader J D. Correlation between laser fluorescence readings and volume of tooth preparation in incipient occlusal caries in vitro. J Esthet Restor Dent 2010; 22: 31-39.

25. Kuhnisch J, Heinrich-Weltzien R. Quantitative lightinduced fluorescence (OLF) - a literature review. Int J Comput Dent 2004; 7: 325-338.

26. Kühnisch J, Bücher $K$, Henschel V, Hickel R. Reproducibility of DIAGNOdent 2095 and DIAGNOdent Pen measurements: results from an in vitro study on occlusal sites. Eur J Oral Sci 2007; 115: 206-211.

27. Eberhart J, Frentzen M, Thoms M et al. New optical techniques for caries detection. Fluorescence-based systems to identify non-cavitated lesions. Paris: Dürr Dental Publication, 2007.

28. Terrer E, Koubi S, Dionne A, Weisrock G, Sarraquigne C, Mazuir A, Tassery H. A new concept in restorative dentistry: light-induced fluorescence evaluator for diagnosis and treatment. Part 1: diagnosis and treatment of initial occlusal caries. J Contemp Dent Pract 2009; 10: E086-E094. 